University of South Florida

DIGITAL COMMONS

Digital Commons @ University of

@ UNIVERSITY OF SOUTH FLORIDA

South Florida

Academic Services Faculty and Staff

Publications

Tampa Library

3-2014

\title{
Critical Information Literacy: A Model for Transdisciplinary Research in Behavioral Sciences
}

Claudia J. Dold

University of South Florida, cdold@usf.edu

Follow this and additional works at: https://digitalcommons.usf.edu/tlas_pub

Part of the Library and Information Science Commons

\section{Scholar Commons Citation}

Dold, Claudia J., "Critical Information Literacy: A Model for Transdisciplinary Research in Behavioral Sciences" (2014). Academic Services Faculty and Staff Publications. 165.

https://digitalcommons.usf.edu/tlas_pub/165

This Article is brought to you for free and open access by the Tampa Library at Digital Commons @ University of South Florida. It has been accepted for inclusion in Academic Services Faculty and Staff Publications by an authorized administrator of Digital Commons @ University of South Florida. For more information, please contact digitalcommons@usf.edu. 
University of South Florida

From the SelectedWorks of Claudia J. Dold

2014

Critical information literacy: A model for
transdisciplinary research in behavioral sciences

Claudia J. Dold 
Critical information literacy: A model for transdisciplinary research in behavioral sciences

\section{Introduction}

The trend in health services is moving toward the integration of primary care and behavioral health, which comprises mental illness, developmental disabilities, dementias, and

substance use. By coordinating assessment and treatment services in one setting, often called the "medical home", the patient's symptoms are evaluated from the primary care and the behavioral health viewpoints, with the goal of providing comprehensive care (Glasgow et al., 2011). Integrated care extends access to behavioral health care across all populations, reduces stigma, and offers hope of early diagnosis and treatment.

Just as primary care and behavioral health care practitioners are reorienting their theory and practice to deliver integrated patient care, librarians may want to examine their own orientation to understanding the integration of information across disciplines (Brown, 2011; Glasgow et al., 2011). Future health practitioners are learning concepts and knowledge structures of their chosen disciplines in today's academic settings. Integrated health care brings together medicine and the behavioral disciplines, including psychology, psychiatry, rehabilitation and mental health counseling, and social work counseling (Peek \& Council, 2013). Each of these disciplines has its own preferred databases, vocabulary, and models; all of them contribute to the mental health and substance use fields. Just as educators are learning to think and work in interdisciplinary realms, so too must librarians working in the clinical sciences keep pace with knowledge integration in order to support faculty and students. This paper examines information literacy models and the usefulness of critical information literacy in bringing diverse fields of knowledge into focus in order to address, understand, and solve broad societal problems. 
Transdisciplinarity is the process of borrowing models and theories from outside the discipline and using them collaboratively in order to create something that transcends the originating disciplines. Transdisciplinary collaboration is increasingly common as fields of knowledge expand and intersect as they do in behavioral health. Behavioral health includes the disorders addressed in the Diagnostic and Statistical Manual of Mental Disorders, $5^{\text {th }}$ edition (DSM-V). Behavior health as a field has been constructed to parallel somatic health. Whereas somatic health addresses physical disorders such as diabetes, cancer, and hypertension within disciplines including medicine, nursing, and public health, behavioral health addresses mental illnesses, developmental disabilities, dementias, and substance use disorders by bringing together disciplines including psychology, psychiatry, counseling, and psychiatric nursing.

Effective library research in the behavioral health fields requires a model that crosses disciplines to bring disparate viewpoints and research methodologies into focus on a shared problem. Consider the DSM-V entry for psychopathy, located within the entry for "antisocial personality disorder" (American Psychiatric Association, 1994). Psychopathy is distinguished by "a pervasive pattern of disregard for, and violation of, the rights of others that begins in childhood or early adolescence and continues into adulthood ...deceitful and manipulative...pattern of impulsivity... irritable...aggressive....Lack of empathy... inflated selfappraisal ... superficial charm...." (pp. 645-647). Research into psychopathy may draw from a number of disciplines, including criminology, neurology, psychology, psychiatry, and sociology, all of which may have theories about the cause, treatment, and/or prognosis of the disorder. While the disorder is a lifetime condition, behavior can change and not all tendencies develop into full expression. Fostering an awareness of empathy can overcome relationship problems for many disorders and allows persons who have a disorder to become productive members of 
society. A transdisciplinary approach to psychopathy allows the researcher to pose a research question and then examine the contributions from a variety of disciplines in order to seek a resolution. An effective model for the integration of those same contributions from a variety of disciplines enables the librarian to organize the information so that it works toward a resolution. To use an analogy, if disciplines use different languages, then the key player is the one who structures the information exchanges so that the research and results of either language group will be comprehensible to all interested parties, and will lead to the resolution of the mutual problem. The following sections discuss attributes of models that are helpful in transdisciplinary research.

\section{The Information Literacy Model}

Librarianship has always focused on bringing together users and information in an efficient and effective manner (Gregory, 2009). Many academic librarians teach process, as opposed to content (Mounce, 2010). They work with students and learning objectives but without the normal academic structure of courses and grades. Academic librarians are concerned with how to measure the contribution and effectiveness of their role on two entities: the education of the university's students, and the attainment of the university's strategic goals. One such measure is information literacy, the term used to describe a person's ability to find, evaluate, and use information competently.

To address the volume of information available to today's students, librarians have shifted the emphasis of their role from gatekeepers of information to teachers about information through an emphasis on information literacy. The Association of College and Research Libraries (ACRL) considered the problems of teaching information literacy and issued guidelines in 2000; 
those guidelines are currently under revision. The Information Literacy Competency Standards for Higher Education (2000) defines "information literacy" as proficiency with a set of skills that enables a person to navigate the universe of information, to make sense of "unfiltered formats, raising questions about its authenticity, validity, and reliability... [because] the sheer abundance of information will not in itself create a more informed citizenry without a complementary cluster of abilities necessary to use information effectively" (Libraries, 2000).

Doherty (2007) and Giles (2002) argue that librarians must teach students to look for bias and gaps in information, and to examine the context in which information is presented. The need is urgent among students new to academia, as they naively venture into the language and thought patterns of disciplines that are unknown to them. Simmons (2005) points out that undergraduate students must learn not only the factual material of their chosen discipline, but also the associated assumptions, epistemologies, and forms of writing, speaking, and researching that are endemic to their field. The refinement of literacy skills is an ongoing process in higher education: doctoral students need well-developed skills to perform comprehensive literature reviews and to produce quality research (Grant \& Berg, 2003), and faculty are expected to be scholars in their field, researching, publishing, and creating new knowledge.

A common assumption in evaluating information literacy classes is this: if the student can perform the tasks, then the instruction in the skill set has been effective. Unfortunately, performance is not a good measure of judgment, and the "economic, legal and social issues surrounding the use of information" can be a matter of judgment (Libraries, 2000).

\section{Criticism of the Information Literacy Model}


Critics of this model of information literacy argue that its focus on behavioral outcomes is misplaced; the real emphasis should be on the information need as posed in the research question (Doherty, 2007; Doherty \& Ketchner, 2005; Giles, 2002). They contend that the ACRL's standards are structured to measure proficiency in a world of information in which educational resources had been selected and categorized by librarians. That world was changed forever by the internet and personal computers, which enabled people to create their own content individually and collectively. Information was made accessible without restriction to a worldwide audience and beyond the control of the library (Dold, 2013). Furthermore, advances in technology created new devices with ever-greater data storage capacity at ever-lower cost. Increasingly more people are using information, and that has led to the creation of more information ("Data, data everywhere," 2010).

Let us consider some statistics. Between July 2000 and June 2010, the number of internet users jumped from 359 million, or 5.9\% of the world population, to 1,966 million, or $28.7 \%$ of the world population (Group, 2013). By the first quarter of 2013, 39\% of the world's population was using the internet, that is, some 2.7 billion people ("ICT Facts and Figures," 2013). The number of domain name registrations rose between December 2000 and 2010 from just under 50 million to over 200 million. The number of websites grew from under 20 million in 2000 to over 200 million by 2010; by December 2012, those numbers were almost 600 million (Zakon, 2011). These trends illustrate the accelerating rate of creation and access to information.

All this information has opened up new data sites, new questions, and new fields for research in mental health. As Hanson and Levin (2013) explain,

Health services research as a field has grown dramatically over the past half century. Unlike biomedical research, health services research addresses observational and quasi-experimental studies, comparative effectiveness studies, economic evaluations, financing and organizational decision making across a 
variety of settings using mixed methodologies. Knowledge and technology transfer is critical, as is the dissemination of applied research and knowledge translation (p. 159).

In addition to greater volumes of information, the variety of information is expanding. The librarian who serves a transdisciplinary research population needs a perspective and skills that will complement the broad, new vision of integrated systems and disciplines.

\section{The Critical Information Literacy Model}

Critical information literacy (CIL) offers an integrated approach to the understanding of information, driven by the patron's query. CIL examines the context of information, the way information works in a discipline and how it differs between disciplines. In the critical information framework, literacy is constantly being defined by its cultural context. CIL recognizes that the professional language, customs and practices of a discipline help create a cultural identity and a shared understanding among those individuals who belong to that cultural community. Elmborg (2006) defines critical information literacy as "more than a set of acquired skills. It involves the comprehension of an entire system of thought and the ways that information flows in the system. Ultimately, it also involves the capacity to critically evaluate the system itself" (p. 196). Individuals, however, start with their own linguistic, cultural, ethnic, and social perspective (Bartesaghi \& Hanson, 2011). By critically examining the very meaning of information, users of information challenge dominant ideologies and move from traditionally accepted authoritative sources to an integrated understanding of the subjective, political, social and economic inflections of information (Dunaway, 2011; Seale, 2010).

To return to the example in the health sciences, psychopathology may be examined qualitatively and quantitatively as behavioral, criminal, and medical attributes; it may also be 
considered as a societal problem on both the local and the global scale. Qualitative research is very different from quantitative research, and no one discipline can offer an academic approach to research that will satisfy the other disciplines. Consequently, a new way of working with knowledge must be employed that will address transdisciplinary research.

\section{An Example from the Behavioral Health Field}

Let us consider a hypothetical example that addresses psychopathy, a specific mental illness. A student poses the research question: What can be done to decrease the number of young people with psychopathic behavior in our society who may end up in the prison system? The student is a master's degree candidate in the criminal justice department of a university. He works with a faculty member. The faculty member researches and writes about psychopathy in juvenile populations. He is not a licensed therapist or a clinician; rather, he is a professor and a researcher. In that context, the professor studies populations of children (persons under 18 years of age) who display callous-unemotional traits, social insensitivity, and other hallmarks of psychopathy. He runs assessment tests on them; all studies are appropriately monitored by the university to ensure that the rights of the subjects are respected. He is working with a medical doctor and neuroscientist whose expertise lies in brain imaging.

In this scenario, we have a student $(S)$ in criminal justice, a researcher $(R)$ in the field of psychopathology, and a medical doctor and neuroscientist $(\mathrm{N})$. They are all looking at the same population at a particular developmental stage. At least three lines of inquiry emerge: psychopathy-as-criminal-behavior (S), psychopathy-as-stage-of-development (R), and psychopathy-as-brain-activity/dysfunction (N). In the academic literature, "psychopathy in 
adolescents" may be a fruitful topic for searches in criminal justice, developmental psychology, and behavioral neuroscience.

In order to work effectively on a shared problem, critical information theory must accommodate the vocabulary and thought trajectories of numerous disciplines. In the criminal justice perspective, students are taught to look at prevention, intervention, and punishment and/or incarceration (Andrews \& Bonta, 2010; Bushway \& Paternoster, 2013). From the developmental psychology perspective, practitioners look at screening and assessment, intervention, and treatment (Blair, Peschardt, Budhani, Mitchell, \& Pine, 2006; Chandler, Fletcher, \& Volkow, 2009; Grigorenko, 2012). From the behavioral neuroscience perspective, researchers look at physiology and presentation of behaviors (Boccardi et al., 2011; Koenigs, Baskin-Sommers, Zeier, \& Newman, 2010; Motzkin, Newman, Kiehl, \& Koenigs, 2011). Each of these three disciplines has a perspective on the identified lines of inquiry but it may not be a mutual perspective.

The librarian sits in the unique position of making sense of these perspectives and teaching the student how to think about them. The librarian's value lies in the ability to understand the vocabulary of each field, as defined in the thesauri associated with each field. By defining the framework of a shared vocabulary, the librarian can show the student where the disciplines overlap and where they diverge. In a transdisciplinary approach, the librarian looks for articles and information that address all three perspectives on psychopathy among adolescents. Using the critical information literacy model, the student may want to examine the problem from each of the lines of inquiry, thinking about how the research participants would frame their view of the problem, based on their discipline. 


\section{Three Focus Areas}

Let us further assume that our hypothetical student considers the sage advice of his esteemed librarian and does in fact analyze the question from the three points of view.

The Criminology Perspective: The first line of inquiry is the criminal justice perspective. Psychopathy in the criminal justice field has to do with a description of traits and behaviors (Babiak et al., 2012). Certain initial questions might be: Who exhibits psychopathic traits? How is the condition defined: As a constellation of behavior problems, a genetic condition, a medical disease, a social phase? Is psychopathy tied to this particular stage of development? Is it tied to gender? Is it stable across world populations or specific to some cultures? What therapies are available to treat the problem and have they been successful? What is the trajectory of an adolescent who is not treated at this stage? Have treatments been tried on younger children and what was the success rate of those outcomes? What methodologies were used to identify, assess and treat psychopathy? Useful articles in criminal justice include those that address the types of behavior exhibited, the incidence and prevalence of disordered behavior, personality inventories used to identify and clarify the disordered behavior, conviction rates, and treatments (Edens, Poythress Jr, Lilienfeld, \& Patrick, 2008; Sheldon \& Krishnan, 2009; Tangney et al., 2012).

Databases that support this line of inquiry include Criminal Justice Abstracts, National Criminal Justice Reference Service (NCJRS) Abstracts, Index to Legal Periodicals and Books Full Text, Medline, and PsycINFO. Interesting articles in the criminal justice perspective include a study of white-collar offenders' psychopathic traits (Ragatz, Fremouw, \& Baker, 2012), and the integration of adaptive strategy and life history theory into criminology (Wiebe, 2012). 
The Developmental Psychology Perspective: The researcher may be interested in identifying and implementing evidence-based treatment prior to entry into the criminal justice system;

consequently, the logical questions concern the physiological and social aspects of psychopathy. These are most often framed in terms of the effects on the individual and on society. How will this person maintain a life? What risks does this personality profile pose to society at large? What supports are available to monitor the person's integration into various communities, and what interventions are in place to enact when the person does not do well? Studies that address arrested stage of brain development would apply, e.g., delayed cortical maturation in several brain areas are implicated in decision making, morality and empathy in boys with callousunemotional conduct problems (De Brito et al., 2009); and critical windows for intervention and treatment, before significant structural brain abnormalities solidify (Finger et al., 2012). Useful databases to search for developmental psychology include CINAHL, the Cochrane databases and other evidence-based medicine (EBM) reviews, PsycINFO, PubMed, and Sociological Abstracts. This constellation of databases examines controlled trials, methodology, tests, models and assessments to determine the validity and extent of psychopathic traits. Recent research topics in developmental psychology include an assessment and management of severe personality disorders (Livesley, 2007), a study in disruptive behavior and interpersonal callousness (Byrd, Loeber, \& Pardini, 2012), and a review of literature on the effectiveness of interventions for individuals with dangerous and severe personality disorders (Vollm, 2009).

The Neuroscience Perspective: The brain imaging scientist looks at understanding the behavior at a neural level. In this framework, the focus is on the brain and brain-reactive chemicals. The 
perspective of psychopathy-as-brain-activity/dysfunction raises questions about the correlation of a particular complex of functions with a disorder. What similarities are there between brain scans of psychopaths? What approaches are available and best-suited to a particular constellation of symptoms: Surgery? Medications? Behavioral modification programs? Current research in brain area function and dysfunction provides insight from environmental and genetic factors (Bezdjian, Raine, Baker, \& Lynam, 2011; Wallace et al., 2012), and offers hope for drug therapy (Vollm et al., 2010). Another study examines brain characteristics that correlate to violent behavior and/or psychopathy as distinguished from lifelong substance use disorders (Schiffer et al., 2011).

Important databases include PubMed, PsycINFO, Web of Science, as well as Genetics Abstracts, and BioMed Central, Biotechnology and BioEngineering Abstracts. All of these databases address biological and medical facets of behavioral sciences. Useful articles in neuroscience examine evidence of genetic risk for psychopathy in children (Viding, Blair, Moffitt, \& Plomin, 2005), the links between psychopathy, genetics and environment (Beaver, Barnes, May, \& Schwartz, 2011), and a broad examination of biological risk factors (Portnoy et al., 2013).

\section{Critical Information Literacy and Librarians}

What does critical information literacy mean to librarians as a profession? It offers a strategy to teach students at all stages in the educational process to evaluate the information at hand in light of the research question. In order to teach evaluation skills, librarians may need to reexamine their own criteria for determining the validity of an information source. Simmons (2005) recommends that librarians become more critical of their own view of information by 
learning the conventions, cultures, and characteristics of their respective academic disciplines. Informed in this way, librarians can "help students see that information is constructed and contested, not monolithic and apolitical" (p. 297). Reading textbooks, taking courses, and talking with professors are ways for the academic librarian to become familiar with the perspective and vocabulary of a discipline.

What guidelines are available to help librarians in this work? In the critical information literacy dynamic, the patron poses a research query and then examines information needs. Doherty (2007) lays out a framework for inquiry:

- What is the purpose of the research?

- What information would be most appropriate to assist in that research?

- How would that information be assessed and used?

- What value is placed on that information, and does it suggest the need for more or different information?

Doherty's framework allows the librarian and the student to consider the context of the question as well as the culture in which the question was raised, the bias of the information sources that are found in the research process, and the patron's own unique perspective on the problem's solution. Real learning occurs when the patron's question and perspective are central to the research and the patron is actively engaged in the analytical process.

Thesauri are invaluable in this work; controlled vocabulary is essential when working in behavioral health and medical research. For example, PsycINFO uses the Thesaurus of Psychological Index Terms, created by the American Psychological Association, as its source for definitions. PsycINFO identifies "antisocial behavior" and "antisocial personality disorder" as terms related to "psychopathy". The scope note provides this definition of psychopathy: "Personality trait marked by egocentricity, impulsivity, and lack of such emotions as guilt and 
remorse, which is particularly prevalent among repeat offenders diagnosed with antisocial

personality disorder" (American Psychological Association, 2013).

PubMed for uses the specialized vocabulary of the medical subject headings (MeSH)

created and maintained by the National Library of Medicine as its reference. When searching in

PubMed for "psychopathy", the program refers the reader to the term, "Antisocial Personality

Disorder", and offers this definition:

A personality disorder whose essential feature is a pervasive pattern of disregard for, and violation of, the rights of others that begins in childhood or early adolescence and continues into adulthood. The individual must be at least age 18 and must have a history of some symptoms of CONDUCT DISORDER before age 15. [From DSM-IV, 1994] (National Library of Medicine, 2014).

The Gale Encyclopedia of Mental Disorders (2003) defines “antisocial personality disorder" as follows:

Also known as psychopathy, sociopathy or dyssocial personality disorder, antisocial personality disorder (APD) is a diagnosis applied to persons who routinely behave with little or no regard for the rights, safety or feelings of others. This pattern of behavior is seen in children or young adolescents and persists into adulthood.... Studies of adopted children indicate that both genetic and environmental factors influence the development. (Haycock, 2003).

In the Gale Encyclopedia of Genetic Disorders (2005), the search for "psychopathy" is directed to "Pervasive Developmental Disorders":

The pervasive developmental disorders, or PDDs, are a group of childhood disorders that manifest during the first years of the child's life. They are marked by severe weaknesses in several areas of development: social interaction, communication, or the appearance of stereotyped behavior patterns and interests. The PDDs are also known as autistic spectrum disorders. As the phrase spectrum disorder suggests, persons with these disorders fall at different points along a fairly wide continuum of disabilities and associated disorders. As defined by DSM-IV, the pervasive developmental disorders include: autistic disorder, Rett syndrome, childhood disintegrative disorder (CDD), Asperger 
syndrome, pervasive developmental disorder not otherwise specified (PDDNOS)."

Further text under the description heading offers this observation:

The PDDs form a diagnostic category intended to identify children with delays in or deviant forms of social, linguistic, cognitive, and motor (muscular movement) development. The category covers children with a wide variety of developmental delays of differing severity in these four broad areas. The precise cause(s) of the PDDs are still obscure, but are assumed to be abnormalities of the central nervous system. (Frey, 2005)

A careful reading of these four descriptions identifies subtle differences: the definitions and descriptions of psychopathy fall into two distinct camps. PsycINFO and the Gale Encyclopedia of Mental Disorders describe behaviors, whereas PubMed and the Gale Encyclopedia of Genetic Disorders describe a disorder with behavior patterns and physical causes. There is no agreement as to the age at which the disorder manifests itself.

In seeking a relevant answer to the query, the patron learns the process of examining a topic from several academic perspectives. However, the CIL approach is not easy to implement. The process becomes complex for both the librarian and the patron, and every patron will have an overload threshold. It is critical that the librarian be aware 1) of that threshold, and 2) that the threshold may change over the course of the research (Budd, 2008).

The prescient librarian will become aware of how the patron is going to use the information, as suggested by Doherty. The librarian could start the conversation by asking if the patron is interested in treatment or in intervention, and then consider the consequences of assessments and/or interventions at various stages in the lifespan. For example, what outcomes might be expected if the assessment or intervention were not implemented now? If the intervention is enacted at a particular point in the subject's trajectory, he or she may avoid incarceration and the follow-on consequences. 
Critical information literacy is a useful model for learning in the behavioral and social sciences where the query often crosses disciplines because the focus is on teaching the patron to find and evaluate information that is useful to the task at hand. In the transdisciplinary modality, information literacy may be defined as the ability to work effectively with information from other disciplines on a problem that will benefit from the expertise of multiple individuals and diverse sources. Using the S-R-N model developed earlier and working on the same research question, let us suppose that $\mathrm{R}$ examines two groups of children with severe conduct problems, those whose parents participated in a two-year-long parenting skills intervention program and those who did not. R may want to ask $\mathrm{S}$ to look into similar interventions and their effectiveness, and $\mathrm{N}$ to read brain scans of both groups. With assistance of $\mathrm{S}$ and $\mathrm{N}, \mathrm{R}$ may be able to identify the effectiveness of a particular set of parenting skills that reduce psychopathic behavior (McDonald, Dodson, Rosenfield, \& Jouriles, 2011).

For another research project, we could start with $\mathrm{N}$ who recognizes similarities in brain scans of adolescents with features of psychopathy, autism, and schizophrenia (Anckarsater, 2006). He might ask $S$ to examine the criminal justice data on the relative frequency with which these individual groups are incarcerated, and ask $\mathrm{R}$ to look into the tests and measures used to diagnose each of these three behavioral problems, or the similarities in behavior modification and drug therapy interventions. In each case, the research focuses on ways to understand the mechanisms that lead to psychopathic behavior and ultimately looks for ways to decrease the number of young people who might become incarcerated.

Transdisciplinary research is an essential tool for approaching the big questions that face society, for example, national public health issues, the impact of global warming, and the effect of increasing population on the world market supply of food and clean water. In the case of 
psychopathy, the librarian and the student may well want to look at its broad implications for safe communities (S), interventions to promote child safety (S), incarceration rates and prison capacity $(\mathrm{S})$, behavioral manifestation that may resemble other behavior disorders $(\mathrm{R})$, the accuracy of tests to identify the disorder $(\mathrm{R})$, the effectiveness of behavior modification programs and drug therapies $(\mathrm{R})$, the genetic/epigenetic and physiological manifestation $(\mathrm{N})$, and drug effectiveness $(\mathrm{N})$. These lines of inquiry cross disciplines but address a shared societal problem.

\section{Conclusion:}

The librarian is in a position to expand the patron's field of awareness beyond the initial query. In the behavioral health field, awareness may include the implications of a targeted outcome in terms of the social consequences, the economic cost to society, and the impact on the health care delivery system and the penal system. Like the primary care provider in a teambased health intervention, the librarian is situated at the intersection of subject-specific perspectives and the patron. The librarian can bring the range of information into focus in order to analyze a research question and enrich the researcher's understanding of the complexity and interconnectedness of the contributing data sources. By guiding researchers to examine information from multiple perspectives and across disciplines, the librarian may help students learn to analyze the bias of information that is available to them, mindful that bias may include the lack of information. Critical information literacy offers a holistic approach to problemsolving that is well-suited to students and practitioners in the behavioral sciences since this discipline examines the individual's health needs in a comprehensive manner. Beginning with another broad question, e.g., How can we improve the health of the cohort born between 1985- 
2005 in order to reduce emergency room visits over the lifespan?, the inquirer may reach out to expertise in traditional medicine, behavioral health, epidemiology, actuarial sciences, economics, nutrition, aging, and criminology, in order to examine aspects of those fields that are relevant to understanding, evaluating and ultimately crafting a solution to the problem. These disciplines deal with a variety of information, both qualitative and quantitative. No one discipline can offer methods and evaluation techniques that are useful to all fields listed. By drawing on multiple disciplines, examining their relevant content in light of the task at hand, and looking for systemic bias, the inquirer may create a series of recommendations that meet goals defined by the research community as meaningful measures of success. Framing the research question is critically important to defining those measures of success.

Collaboration is an essential component of critical information literacy in order to conduct transdisciplinary research. The librarian may play a role here too as an information specialist, by focusing the query and research on essential information to solve the problem and challenging the disciplinary silos concerning research methods and evaluation. Controlled vocabulary and thesauri are critical tools for transdisciplinary research. Depending on the problem at hand, the librarian and the inquirer may be the only members of the research team who are not strongly allied with a particular disciplinary tradition of methods and evaluations. The academic librarian has a unique qualification: as a function of her role in the university, she has access to research within and across disciplines. She may already have a working relationship with some of the members of the research team. She may have friends in specific disciplines that she may call upon to clarify her own understanding or to explain potential points of linguistic confusion. The librarian's interdisciplinary network of fellow librarians and faculty makes her an ideal player in the transdisciplinary research process. 
Behavioral health is just one of a growing number of transdisciplinary sciences. The transdisciplinary model will be increasingly important as information becomes available to address major societal problems. 


\section{References}

American Psychiatric Association. (1994). Psychopathy. Diagnostic and statistical manual of mental disorders, Fourth ed. Washington, DC: American Psychiatric Association.

American Psychological Association. (2013). Psychopathy. Thesaurus of psychological index terms. Washington, DC: American Psychological Association.

Anckarsater, H. (2006). Central nervous changes in social dysfunction: Autism, aggression, and psychopathy. Brain Research Bulletin, 69(3), 259-265. doi:

10.1016/j.brainresbull.2006.01.008

Andrews, D. A., \& Bonta, J. (2010). Rehabilitating criminal justice policy and practice. Psychology, Public Policy, and Law, 16(1), 16. doi: 10.1037/a0018362

Association of College and Research Libraries (2000). Information literacy competency standards for higher education. Retrieved June 24, 2013 from http://www.ala.org/acrl/standards/informationliteracycompetency

Babiak, P., Folino, J., Hancock, J., Hare, R., Logan, M., Mayer, E. L., . . Woodworth, M. (2012, July). Psychopathy. FBI Law Enforcement Bulletin. Retrieved May 16, 2013, from http://www.fbi.gov/stats-services/publications/law-enforcement-bulletin/july-2012

Bartesaghi, M., \& Hanson, A. (2011). Understanding social networking: The benefit of discourse analysis. In D. Cook \& L. Farmer (Eds.), Using qualitative methods in action research: How librarians can get to the why of data (pp. 47-63). Chicago, IL: ACRL.

Beaver, K. M., Barnes, J. C., May, J. S., \& Schwartz, J. A. (2011). Psychopathic personality traits, genetic risk, and gene-environment correlations. Criminal Justice and Behavior, 38(9), 896-912. doi: http://dx.doi.org/10.1177/0093854811411153 
Bezdjian, S., Raine, A., Baker, L. A., \& Lynam. (2011). Psychopathic personality in children: Genetic and environmental contributions. Psychological Medicine, 41(3), 589-600. doi: http://dx.doi.org/10.1017/S0033291710000966

Blair, R. J. R., Peschardt, K. S., Budhani, S., Mitchell, D. G. V., \& Pine, D. S. (2006). The development of psychopathy. Journal of Child Psychology and Psychiatry, 47(3-4), 262276. doi: 10.1111/j.1469-7610.2006.01596.x

Boccardi, M., Frisoni, G. B., Hare, R. D., Cavedo, E., Najt, P., Pievani, M., . . Tiihonen, J. (2011). Cortex and amygdala morphology in psychopathy. Psychiatry Research, 193(2), 85-92. doi: 10.1016/j.pscychresns.2010.12.013; 10.1016/j.pscychresns.2010.12.013

Brown, R. L. (2011). Configuring health care for systematic behavioral screening and intervention. Population Health Management, 14(6), 299-305. doi: 10.1089/pop.2010.0075

Budd, J. (2008). Cognitive growth, instruction, and student success. College \& Research Libraries, 69, 12.

Bushway, S. D., \& Paternoster, R. (2013). Desistance from crime: A review and ideas for moving forward. In C. L. Gibson \& M. D. Krohn (Eds.), Handbook of life-course criminology: Emerging trends and directions for future research (pp. 213-231). New York: Springer Science+Business Media. Retrieved from http://link.springer.com/content/pdf/10.1007\%2F978-1-4614-5113-6_13.pdf. doi: 10.1007/978-1-4614-5113-6_13

Byrd, A. L., Loeber, R., \& Pardini, D. A. (2012). Understanding desisting and persisting forms of delinquency: The unique contributions of disruptive behavior disorders and 
interpersonal callousness. Journal of Child Psychology and Psychiatry, 53(4), 371-380. doi: 10.1111/j.1469-7610.2011.02504.x

Chandler, R. K., Fletcher, B. W., \& Volkow, N. D. (2009). Treating drug abuse and addiction in the criminal justice system: Improving public health and safety. Journal of the American Medical Association, 301(2), 183-190. doi: 10.1001/jama.2008.976

Data, data everywhere (2010, Feb 27). The Economist, 394. 3-S.5.

De Brito, S. A., Mechelli, A., Wilke, M., Laurens, K. R., Jones, A. P., Barker, G. J., . . Viding, E. (2009). Size matters: Increased grey matter in boys with conduct problems and callous-unemotional traits. Brain, 132(Pt 4), 843-852. doi: 10.1093/brain/awp011

Doherty, J. J. (2007). No shhing: Giving voice to the silenced: An essay in support of critical information literacy. Library Philosophy \& Practice, 9(3), 1-8.

Doherty, J. J., \& Ketchner, K. (2005). Empowering the intentional learner: A critical theory for information literacy instruction. Library Philosophy \& Practice, 8(1), 1-10.

Dold, C. J. (2013). The role of librarians in academic success. Journal of Systemics, Cybernetics and Informatics, 11(2), 1-5.

Dunaway, M. (2011). Web 2.0 and critical information literacy. Public Services Quarterly, 7(3), 149-157. doi: 10.1080/15228959.2011.622628

Edens, J. F., Poythress Jr, N. G., Lilienfeld, S. O., \& Patrick, C. J. (2008). A prospective comparison of two measures of psychopathy in the prediction of institutional misconduct. Behavioral Sciences \& the Law, 26(5), 529-541. doi: 10.1002/bs1.823

Elmborg, J. (2006). Critical information literacy: Implications for instructional practice. Journal of Academic Librarianship, 32(2), 8. 
Finger, E. C., Marsh, A., Blair, K. S., Majestic, C., Evangelou, I., Gupta, K., . . Blair, R. J. (2012). Impaired functional but preserved structural connectivity in limbic white matter tracts in youth with conduct disorder or oppositional defiant disorder plus psychopathic traits. Psychiatry Research: Neuroimaging, 202(3), 239-244. doi: http://dx.doi.org/10.1016/j.pscychresns.2011.11.002

Frey, R. J. (2005). Pervasive developmental disorders. In B. Narins (Ed.), The Gale encyclopedia of genetic disorders (2nd ed., Vol. 2, pp. 1007-1010). Detroit: Gale. Retrieved from USF Libraries at http://go.galegroup.com/ps/infomark.do?action=interpret\&actionString=DO_DISPLAY_ ABOUT_PAGE\&tabID=T002\&prodId=GVRL\&docId=CX3451599999\&type=aboutBoo $\mathrm{k} \&$ version $=1.0 \&$ authCount $=1$

Giles, G. (2002). 'Fair go'? Equality? The people's movement for reconciliation (ANTaR) and critical information literacy. Australian Library Journal, 51(3), 203-218.

Glasgow, R. E., Dickinson, P., Fisher, L., Christiansen, S., Toobert, D. J., Bender, B. G., . . . Estabrooks, P. A. (2011). Use of RE-AIM to develop a multi-media facilitation tool for the patient-centered medical home. Implementation Science, 6, 118-118. doi: $10.1186 / 1748-5908-6-118$

Grant, M., \& Berg, M. (2003). Information literacy integration in a doctoral program. Behavioral \& Social Sciences Librarian, 22(1), 115-128.

Gregory, V. L. (2009). Education for library and information science professionals. In Mehdi Kushrow-Pour (Ed.), Encyclopedia of information science and technology, $2^{\text {nd }}$ ed. doi: 10.4018/978-1-60566-026-4.ch198 
Grigorenko, E. L. (2012). At the junction of personality theories: Working with juvenile offenders. In E. L. Grigorenko (Ed.), Handbook of juvenile forensic psychology and psychiatry (pp. 253-279). New York: Springer.

Miniwatts Marketing Group. (2013, May 16). Internet World Stats. Retrieved June 7, 2013, from http://www.internetworldstats.com/stats.htm

Hanson, A., \& Levin, B. L. (2013). Mental Health Informatics. New York: Oxford University Press.

Haycock, D. A. (2003). Antisocial personality disorder. In M. Harris \& E. Thackerey (Eds.), The Gale encyclopedia of mental disorders (Vol. 1, pp. 68-71). Detroit: Gale. Retrieved from USF Libraries at http://go.galegroup.com/ps/infomark.do?type=aboutBook\&docId=CX3405799999\&tabI D=T002\&actionString=DO_DISPLAY_

ICT Facts and Figures. (2013). The World in 2013. Retrieved June 15, 2013, from http://www.itu.int/en/ITU-D/Statistics/Documents/facts/ICTFactsFigures2013.pdf

Koenigs, M., Baskin-Sommers, A., Zeier, J., \& Newman, J. P. (2010). Investigating the neural correlates of psychopathy: A critical review. Molecular Psychiatry, 16(8), 792-799.

Livesley, W. J. (2007). A framework for integrating dimensional and categorical classifications of personality disorder. Journal of PersonalityDisorders, 21(2), 199-224. doi: 10.1521/pedi.2007.21.2.199

McDonald, R., Dodson, M. C., Rosenfield, D., \& Jouriles, E. N. (2011). Effects of a parenting intervention on features of psychopathy in children. Journal of Abnormal Child Psychology, 39(7), 1013-1023. http://www.nlm.nih.gov/hmd/collections/digital/MeSH/mesh.html 
Motzkin, J. C., Newman, J. P., Kiehl, K. A., \& Koenigs, M. (2011). Reduced prefrontal connectivity in psychopathy. The Journal of Neuroscience, 31(48), 17348-17357. doi: 10.1523/JNEUROSCI.4215-11.2011

Mounce, M. (2010). Working together: Academic librarians and faculty collaborating to improve students' information literacy skills: A literature review 2000-2009. The Reference Librarian, 51, 300-320.

National Library of Medicine. (2014). Antisocial Personality Disorder. Medical Subject Headings [MeSH]. Rockville, MD. RetrievedNovember 20, 2013 from http://www.nlm.nih.gov/mesh/MBrowser.html

Peek, C. J., \& Council, N. I. A. (2013). Lexicon for behavioral health and primary care integration: Concepts and definitions developed by expert consensus. AHRQ Publication No. AHRQ 13 -IP001-EF Retrieved from http://integrationacademy.ahrq.gov/sites/default/files/Lexicon.pdf

Portnoy, J., Gao, Y., Glenn, A., Niv, S., Peskin, M., Rudo-Hutt, A., . . Raine, A. (2013). The biology of childhood crime and antisocial behavior. In C. L. Gibson \& M. D. Krohn (Eds.), Handbook of life-course criminology (pp. 21-42). New York: Springer.

Ragatz, L. L., Fremouw, W., \& Baker, E. (2012). The psychological profile of white-collar offenders: Demographics, criminal thinking, psychopathic traits, and psychopathology. Criminal Justice \& Behavior, 39(7), 978-997. doi: 10.1177/0093854812437846

Rashid, J. R., Spengler, R. F., Wagner, R. M., Melanson, C., Skillen, E. L., Mays, R. A., . . Long, J. A. (2009). Eliminating health disparities through transdisciplinary research, cross-agency collaboration, and public participation. American Journal of Public Health, 99(11), 1955-1961. doi: 10.2105/Ajph.2009.167932 
Schensul, S. L., Nastasi, B. K., \& Verma, R. K. (2006). Community-based research in India: A case example of international and transdisciplinary collaboration. American Journal of Community Psychology, 38(1-2), 95-111. doi: 10.1007/s10464-006-9066-z

Schiffer, B., Muller, B. W., Scherbaum, N., Hodgins, S., Forsting, M., Wiltfang, J., .. . Leygraf, N. (2011). Disentangling structural brain alterations associated with violent behavior from those associated with substance use disorders. General Archives of Psychiatry, 68(10), 1039-1049. doi: http://dx.doi.org/10.1001/archgenpsychiatry.2011.61

Seale, M. (2010). Information literacy standards and the politics of knowledge production: Using user-generated content to incorporate critical pedagogy. In M. Accardi, E. Drabinski \& A. Kumbier (Eds.), Critical library instruction: Theories and methods (pp. 221-235). Duluth, MN: Library Juice Press.

Sheldon, K., \& Krishnan, G. (2009). The clinical and risk characteristics of patients admitted to a secure hospital-based Dangerous and Severe Personality Disorder unit. British Journal of Forensic Practice, 11(3), 19-27. Retrieved from http://search.proquest.com/docview/704839952?accountid=14745

Simmons, M. J. (2005). Librarians as disciplinary discourse mediators: Using genre theory to move toward critical information literacy. portal: Libraries and the Academy, 5(3), 297 311. Retrieved from http://muse.jhu.edu/journals/portal_libraries_and_the_academy/toc/pla5.3.html Tangney, J. P., Stuewig, J., Furukawa, E., Kopelovich, S., Meyer, P. J., \& Cosby, B. (2012). Reliability, validity, and predictive utility of the 25-item Criminogenic Cognitions Scale (CCS). Criminal Justice \& Behavior, 39(10), 1340-1360. doi:

$10.1177 / 0093854812451092$ 
Viding, E., Blair, R. R., Moffitt, T. E., \& Plomin, R. (2005). Evidence for substantial genetic risk for psychopathy in 7-year-olds. Journal of Child Psychology and Psychiatry and Allied Disciplines, 46(6), 592-597. doi: http://dx.doi.org/10.1111/j.1469-7610.2004.00393.x

Vollm, B. (2009). Assessment and management of dangerous and severe personality disorders. Current Opinion in Psychiatry, 22(5), 501-506. doi: 10.1097/YCO.0b013e32832c9cdc

Vollm, B., Richardson, P., McKie, S., Reniers, R., Elliott, R., Anderson, I. M., . . Deakin, B. (2010). Neuronal correlates and serotonergic modulation of behavioural inhibition and reward in healthy and antisocial individuals. Journal of Psychiatric Research, 44(3), 123131. doi: http://dx.doi.org/10.1016/j.jpsychires.2009.07.005

Wallace, G. L., Shaw, P., Lee, N. R., Clasen, L. S., Raznahan, A., Lenroot, R. K., . . Giedd, J. N. (2012). Distinct cortical correlates of autistic versus antisocial traits in a longitudinal sample of typically developing youth. The Journal of Neuroscience, 32(14), 4856-4860. doi: http://dx.doi.org/10.1523/JNEUROSCI.6214-11.2012

Wiebe, R. P. (2012). Integrating criminology through adaptive strategy and life history theory. Journal of Contemporary Criminal Justice, 28(3), 346-365. doi: $10.1177 / 1043986212450231$

Zakon, R. H. (2011). Hobbes’ Internet Timeline 10.2. Retrieved June 8, 2013, from http://www.zakon.org/robert/internet/timeline/ 